\title{
Histological and immunohistochemical study of hepatitis $B$ virus in human immunodeficiency virus infection
}

\author{
R D Goldin, D E Fish, A Hay, J A Waters, M J McGarvey, J Main, H C Thomas
}

\begin{abstract}
Because the risk factors for human immunodeficiency virus (HIV) infection and hepatitis $B$ (HBV) are similar and therefore coinfection is not uncommon, a detailed histological and immunohistochemical study of chronic hepatitis $B$ infection in a group of $20 \mathrm{HIV}$ positive Caucasian males (who did not have AIDS) and 30 HIV negative controls was undertaken. Using both the conventional histological classification and the Knodell histological activity index it was shown that HIV negative patients were more likely to have active disease and also more scarring than HIV positive patients. Hepatitis B surface antigen (HBsAg) expression was not significantly different between the two groups but expression of hepatitis Be antigen (HBeAg) and HBVDNA polymerase was greater in those who were HIV positive. HIV positive patients are therefore more likely to have immunohistochemical markers of active viral replication, although histologically, liver disease is less severe.
\end{abstract}

These findings have important implications for assessing the biopsy specimens in this group of patients and for treatment strategies aimed at improving their immune function.

Liver injury sustained as a result of hepatitis B virus $(\mathrm{HBV})$ infection depends on viral replication and immune lysis of infected hepatocytes by $\mathrm{T}$ lymphocytes. ${ }^{1}$ Infection with $\mathrm{HBV}$ and human immunodeficiency virus (HIV) are found in similar risk populations such as homosexuals and intravenous drug addicts and coinfection with these viruses is therefore common. It is known that infection with HIV produces immunosuppression and, in particular, results in diminished $\mathrm{T}$ lymphocyte function. Coinfection with HIV may therefore modify the natural history of the HBV infection. Studies have shown that in HIV positive patients there is increased $\mathrm{HBV}$ antigen display with a trend towards a milder histological grade of liver disease and improvement in biochemical markers of liver cell damage. ${ }^{2-5}$

Our aim was to undertake a detailed histological and immunohistochemical study of the effect of coinfection with HBV and HIV to see in which ways the histological picture of liver disease varied and how markers of HBV infection and replication differed.
Methods

Patients chosen for the study were male Caucasians who were known to have had positive serology HBV surface antigen (HBsAg) for longer than six months. The patients had been tested for HIV antibodies using a commercial enzyme linked immunosorbent assay (ELISA) technique (Wellcome Laboratories, Beckenham, Kent). These comprised $20 \mathrm{HIV}$ positive men (age range 27-45 years, mean 43 years) and $30 \mathrm{HIV}$ negative men (age range 34-63 years, mean 48 years). None of the HIV positive patients had AIDS as defined by the American Centers for Disease Control criteria. ${ }^{6}$

Liver biopsy was performed under local anaesthetic with a Menghini needle. The core of liver was fixed for at least 24 hours in $10 \%$ unbuffered formol-saline, processed, embedded in paraffin wax and 20 sections $6 \mu \mathrm{m}$ thick were cut. Sections were stained with haematoxylin and eosin, haematoxylin van Gieson, diastase and periodic acid Schiff, orcein, Masson's trichrome, reticulin and Perls's stain. The biopsy specimens were assessed histologically and placed into standard disease categories (chronic persistent hepatitis $(\mathrm{CPH})$, chronic lobular hepatitis (CLH), and chronic active hepatitis (CAH) with or without cirrhosis). ${ }^{7}$ Each biopsy specimen was scored separately (0-4) for necrosis, inflammation, and fibrosis to give a total Knodell histological activity index ranging from $0-12 .^{8}$

\section{IMMUNOHISTOCHEMICAL PROCEDURES}

Unstained paraffin wax embedded sections were dewaxed in xylene and decreasing concentrations of alcohol to water. Endogenous peroxidase was blocked by incubation of the sections with $1^{\circ}$, hydrogen peroxide in methanol for 15 minutes. No protease or trypsin digestion was required. Sections were washed in TRIS-buffered saline (TBS), $0.05 \mathrm{M}$ ( $\mathrm{pH}$ $7 \cdot 6$ ) and then incubated in normal swine serum (diluted $1 / 5$ in TBS) for 15 minutes, and then washed again in TBS three times. The sections were incubated with undiluted primary antibody for two hours. The antibodies used were murine monoclonal antibodies prepared against $\mathrm{HBsAg}$ and $\mathrm{HBeAg}^{9}$ and a rabbit polyclonal antibody prepared against $\mathrm{HBV}$ DNA polymerase. After another wash in TBS the sections were incubated for 30 minutes with $1 / 300$ biotinylated rabbit anti-mouse immunoglobulin or swine anti-rabbit (both from Dako), washed again in TBS, and incubated for a further 30 minutes with avidin 
Table 1 Comparison of Knodell histological activity index in HIV positive and negative male Caucasians with chronic HBV infection

\begin{tabular}{lll}
\hline Histological activity index & HIV positive $(n=20)$ & HIV negative $(n=30)$ \\
\hline Inflammation necrosis & Median $=3($ range 1-5) & Median $=6$ (range 2- 8) \\
Fibrosis & Median $=0($ range 0-4) & Median $=1 \cdot 5($ range 0-4) \\
Total histological activity index & Median $=3($ range 1-7) & Median $=9 \quad($ range 3-11) \\
\hline${ }^{\star p}<0.01$. & &
\end{tabular}

biotin complex ( $1 \mu \mathrm{l}$ of avidin and $1 \mu \mathrm{l}$ of peroxidase conjugated biotin in $125 \mu$ l of TBS). The slides were washed in TBS and the peroxidase was developed with a solution of $10 \mathrm{mg}$ of diaminobenzidine in $10 \mathrm{ml}$ of TBS and $0.08 \mathrm{ml}$ of $3 \%$ hydrogen peroxide for 10 minutes. A known positive and negative control were incorporated in each batch. The sections were counterstained with haematoxylin, dehydrated, and mounted.

The results of the immunohistochemical techniques were graded semiquantitatively depending on the proportion of hepatocytes that stained $(0=$ no staining, $1=0-10 \%$ of cells, $2=10-25 \%$ of cells, $3=25-50 \%$ of cells and $4=$ more than $50 \%$ of cells). Sections were also stained with a polyclonal antibody raised against the $\delta$ antigen of the hepatitis $\delta$ virus (HDV). No cases of positive staining for $\delta$ antigen were found. Staining with a murine anti-HBc antibody was unsuccessful as would be expected on formalin fixed tissue rather than frozen sections. ${ }^{210}$

The results were analysed using the MannWhitney $U$ test for non-parametric data, a $\chi^{2}$ test, and a rank correlation coefficient. ${ }^{71}$

\section{Results}

The histological findings are summarised in tables 1 and 2 and the immunohistochemical findings in table 3.

Male Caucasians coinfected with HIV had a significantly lower Knodell histological activity index $(p<0.01)$ (table 1$)$ than HIV negative controls. A significant association between HIV antibody state and histological grade of chronic liver disease was shown, with $\mathrm{CPH}$ being more common and $\mathrm{CAH}$ being less common in the HIV positive than in the HIV negative men $\left(\chi^{2}=12.58, \mathrm{p}<0.001\right)$. Six of the HIV negative men had cirrhosis compared with only one of the $20 \mathrm{HIV}$ positive men, but the numbers involved are too small to be analysed. The amount of lobular inflammation did not differ between the two groups.

Liver biopsy specimens from HIV positive patients showed significantly greater expression of $\mathrm{HBeAg}$ and HBV DNA polymerase compared with HIV negative controls, as

Table 2 Histological categories in HIV positive and negative Caucasian men with chronic $H B V$ infection

\begin{tabular}{lll}
\hline Histology & $\begin{array}{l}\text { HIV } \\
\text { positive } \\
(n=20)\end{array}$ & $\begin{array}{l}\text { HIV } \\
\text { negative } \\
(n=30)\end{array}$ \\
\hline CPH & 16 & 10 \\
CAH (without cirrhosis) & 2 & 14 \\
CLH & 1 & 0 \\
Cirrhosis with CAH & 0 & 4 \\
Cirrhosis & 1 & 2 \\
\hline
\end{tabular}

Table 3 Hepatitis $B$ viral antigen and DNA polymerase expression in HIV positive and HIV negative Caucasian men

\begin{tabular}{lccc}
\hline Viral antigen expression & $\begin{array}{c}H I V \\
\text { positive }\end{array}$ & $\begin{array}{l}H I V \\
\text { negative }\end{array}$ \\
\hline HBsAg $^{\star}$ & 0 & 5 & 14 \\
& $1+$ & 14 & 11 \\
& $2+$ & 1 & 5 \\
& $3+$ & 0 & 0 \\
HBeAg ${ }^{+}$ & $4+$ & 0 & 0 \\
& 0 & 3 & 22 \\
& $1+$ & 5 & 7 \\
& $2+$ & 6 & 1 \\
HBV DNA & $3+$ & 0 & 0 \\
polymerase ${ }^{+}$ & $4+$ & 4 & 0 \\
& $1+$ & 2 & 24 \\
& $2+$ & 8 & 3 \\
& $4+$ & 5 & 3 \\
& $4+$ & 1 & 0 \\
\hline
\end{tabular}

$\star$ Not significant. $+p<0.01$.

assessed by immunohistochemistry ( $p<0.01$ ) (table 3). The expression of HBsAg does not, however, seem to be influenced by HIV state. There was a strong positive correlation between immunohistochemical staining for $\mathrm{HBeAg}$ and HBV DNA polymerase expression as would be expected as both are markers of HBV replication (rank correlation coefficient $r$ $=0.73, \mathrm{p}<0.001)($ table 3$)$.

\section{Discussion}

The aim of this study was to assess the effect of coinfection with HIV on the histological and immunohistochemical changes seen in chronic HBV infection. Only Caucasians were studied to exclude those cases, especially common in the Chinese, who may have acquired their HBV by vertical transmission and who tend to have less severe disease as assessed histologically. Patients with AIDS were excluded because it is more difficult to assess the effects of the many other disease processes and their treatments, which may coexist.

Although other groups of workers have looked at the association of HBV and HIV, these have not looked at the histological findings in the liver in detail. Chronic active hepatitis, with and without cirrhosis, is more common in HIV negative patients, and the score for the inflammatory component of the Knodell index is higher. Thus two different methods of assessing the activity of the HBV infection show that it is greater in HIV negative patients. Furthermore, the degree of scarring was also greater in HIV negative patients as measured by the fibrosis component of the Knodell index or the incidence of cirrhosis.

An immunohistochemical study of $\mathrm{HBV}$ antigen expression shows that $\mathrm{HBeAg}$ and HBV DNA polymerase expression is significantly increased in HIV positive patients ( $p<$ 0.01 ) (table 3). This indicates that viral replication is greater in these patients. The HBV DNA polymerase is a new immunohistochemical marker for $\mathrm{HBV}$ replication and it correlates well with $\mathrm{HBeAg}$ expression.

The low histological activity indices in the presence of high levels of $\mathrm{HBV}$ replication can be explained by the fact that hepatocyte 
damage in HBV depends on cytotoxic T lymphocyte activity directed against hepatocytes expressing $\mathrm{HBcAg}$, ${ }^{1}$ and it is likely that HIV positive patients have subclinical immunosuppression even if they don't have AIDS. ${ }^{23}$ Long term follow up studies will be necessary to assess the effect of these changes on the natural history of the disease process.

These findings have two important implications. Firstly, conventional histological grading will underestimate the amount of HBV and level of HBV replication in the absence of immunohistochemical techniques to show the presence of viral antigens. Secondly, any treatment for HIV which improves T lymphocyte function may increase the histological activity of chronic HBV infection of the liver.

We thank Jane Wadsworth, Academic Department of Community Medicine, for statistical advice.

1 Gerber MA, Thung SN. Molecular and cellular pathology of hepatitis B. Lab Invest 1985;52:572-88.
2 McDonald JA, Harris S, Waters JA, et al. Effect of human immunodeficiency virus (HIV) infection on chronic hepatitis B viral antigen display. J Hepatol 1987;4:337-42.

3 Perillo RP, Regeustein FG, Roodman ST. Chronic hepatitis $B$ in asymptomatic homosexual men with antibody to the human immunodeficiency virus. Ann Intern Med 1986; 105:382-3.

4 Krogsgaard $\mathrm{K}$, Lindhardt BO, Nielsen JO, et al. The influence of HTLV-111 infection on the natural history of hepatitis B virus infection in male homosexual $\mathrm{HBsAg}$ carriers. J Hepatol 1987;7:37-41.

5 Pastore G, Santantonio T, Monno L, et al. Effects of HIV superinfection on HBV replication in a chronic $\mathrm{HBsAg}$ superinfection on HBV replication in a chronic

6 Centers for Disease Control. Classification system for human T-lymphotropic virus type 111/lymphadenopathy-associated virus infection. Ann Intern Med 1986; 105:234-7.

7 Bianchi L, De Groote J, Desmet VJ, et al. Acute and chronic hepatitis revisited. Review by an International group. Lancet 1977; ii:914-9.

8 Knodell RG, Ishak KG, Black WC, et al. Formulation and application of a numerical scoring system for assessing histological activity in asymptomatic chronic active histological activity in asymptom
hepatitis. Hepatology 1981;1:431-5.

9 Waters JA, Jowett TB, Thomas HC. Identification of a dominant immunogenic epitope of the nucleocapsid (HBc) of the hepatitis B virus. J Med Virol 1986;19:79-86.

10 Katumo S, Arao M, Yoshioka K, et al. Distribution of $\mathrm{HBcAg}$ in hepatitis B detected by immunoperoxidase staining with three different preparations of anti-HBc antibodies. J Clin Pathol 1989;42:284-8.

11 Armitage P. Statistical methods in medical research. 2nd Edition. Oxford: Blackwell Scientific, 1973. 